\title{
Polyclonal HER2-specific antibodies induced by vaccination mediate receptor internalization and degradation in tumor cells
}

Xiu-Rong Ren ${ }^{1}$, Junping Wei ${ }^{2}$, Gangjun Lei ${ }^{2}$, Jiangbo Wang ${ }^{1}$, Jiuyi Lu', Wenle Xia ${ }^{3}$, Neil Spector ${ }^{2,3}$, Larry S Barak ${ }^{4}$, Timothy M Clay ${ }^{5}$, Takuya Osada ${ }^{2}$, Erika Hamiltonn ${ }^{6}$, Kimberly Blackwell ${ }^{6}$, Amy C Hobeika ${ }^{2}$, Michael A Morse ${ }^{2,3}$, $\mathrm{H}$ Kim Lyerly ${ }^{2,7^{*}}$ and Wei Chen ${ }^{1,2^{*}}$

\begin{abstract}
Introduction: Sustained HER2 signaling at the cell surface is an oncogenic mechanism in a significant proportion of breast cancers. While clinically effective therapies targeting HER2 such as mAbs and tyrosine kinase inhibitors exist, tumors overexpressing HER2 eventually progress despite treatment. Thus, abrogation of persistent HER2 expression at the plasma membrane to synergize with current approaches may represent a novel therapeutic strategy.
\end{abstract}

Methods: We generated polyclonal anti-HER2 antibodies (HER2-VIA) by vaccinating mice with an adenovirus expressing human HER2, and assessed their signaling effects in vitro and anti-tumor effects in a xenograft model. In addition, we studied the signaling effects of human HER2-specific antibodies induced by vaccinating breast cancer patients with a HER2 protein vaccine.

Results: HER2-VIA bound HER2 at the plasma membrane, initially activating the downstream kinases extracellular signal-regulated protein kinase $1 / 2$ and Akt, but subsequently inducing receptor internalization in clathrin-coated pits in a HER2 kinase-independent manner, followed by ubiquitination and degradation of HER2 into a 130 kDa fragment phosphorylated at tyrosine residues 1,221/1,222 and 1,248. Following vaccination of breast cancer patients with the HER2 protein vaccine, HER2-specific antibodies were detectable and these antibodies bound to cell surface-expressed HER2 and inhibited HER2 signaling through blocking tyrosine 877 phosphorylation of HER2. In contrast to the murine antibodies, human anti-HER2 antibodies induced by protein vaccination did not mediate receptor internalization and degradation.

Conclusion: These data provide new insight into HER2 trafficking at the plasma membrane and the changes induced by polyclonal HER2-specific antibodies. The reduction of HER2 membrane expression and HER2 signaling by polyclonal antibodies induced by adenoviral HER2 vaccines supports human clinical trials with this strategy for those breast cancer patients with HER2 therapy-resistant disease.

\section{Introduction}

Breast cancers overexpressing HER2 have an aggressive clinical course. Despite the proven effectiveness of the HER2-specific mAb trastuzumab (Herceptin) and the dual epidermal growth factor receptor (EGFR) and HER2

\footnotetext{
* Correspondence: Iyerl001@mc.duke.edu; w.chen@duke.edu

'Department of Medicine, Duke University Medical Center, 595 Lasalle Street, Durham, NC 27710, USA

2Duke Comprehensive Cancer Center, Duke University Medical Center, 203

Research Drive, Durham, NC 27710, USA

Full list of author information is available at the end of the article
}

receptor tyrosine kinase inhibitor lapatinib (Tykerb), disease progression and the rate of cancer-related deaths remain unacceptably high. HER2 remains overexpressed on cells that develop resistance to either anti-HER2 mAbs or tyrosine kinase inhibitor, which may be partly responsible for these failures in therapy, because additional blockade by combining trastuzumab and lapatinib provides clinical benefit $[1,2]$. Recent preclinical and clinical studies using novel mAbs that prevent HER2 and HER3 dimerization also appear to be effective, suggesting

\section{Biomed Central}


that persistent HER2 signaling is a cause of treatment failure $[3,4]$. The depletion of HER2 from the surface of resistant tumors cells by novel agents may therefore provide a means for reducing tumor aggressiveness and improving patient survival.

HER2/neu together with HER1 (EGFR), HER3, and HER4 comprise the EGFR family of plasma membrane tyrosine kinases $[5,6]$. HER2, in contrast to the other three receptors, is an orphan with no recognized endogenous ligand; nevertheless, plasma membrane-localized HER2 signals as a consequence of intrinsic tyrosine kinase activity. The HER2 receptor forms homodimers as well as heterodimer pairs with HER1, HER3, or HER4 [7-9]. HER $2 / 3$ heterodimers are the most potent activators of the phosphatidylinositol-3-kinase (PI3K)-Akt cell survival pathway. The binding of the HER1 ligand epidermal growth factor (EGF) and the HER3 ligand neuregulin to extracellular domains of HER1 and HER3, respectively, leads to receptor activation and the formation of homodimers or heterodimers. The increased kinase activity of heterodimeric partners leads to the transactivation of HER2 and phosphorylation of tyrosine residues including tyrosines $1,221 / 1,222$ and 1,248 in the cytosolic tail of HER2. These phosphotyrosine residues serve as docking sites for SH2-containing and PTB-containing adaptor proteins that link HERs to downstream intracellular signaling cascades, including Ras, extracellular signal-regulated protein (ERK) kinase, phospholipase C gamma, PI3K, Akt and signal transducer and activator of transcription (STAT3)3 pathways.

HER1 undergoes a rapid and pronounced EGF-induced internalization from the plasma membrane as part of a dynamic clathrin-directed trafficking process that plays a key role in regulating its membrane expression, intracellular signaling, and downregulation [10]. HER1 contains canonical motifs that, following its autophosphorylation, directly bind to clathrin and clathrin-associated adaptor proteins. While it has been reported that HER2 co-internalizes with HER1 [11], internalization of HER2 alone from a population of HER2 homodimers has not been observed, even though HER2 contains intracellular motifs that are localized similarly to those present in HER1 [12].

In this report we show that, in comparison with the mAb trastuzumab, exposure of cell-surface HER2 to polyclonal anti-HER2 antibody generated in mice promotes rapid receptor internalization and degradation, accompanied by phosphorylation of the downstream kinasesERK1/ 2 and Akt. Prolonged exposure to the polyclonal antiHER2 antibody is characterized by significant HER2 internalization, ubiquitination and degradation, a dramatic reduction in plasma membrane HER2 expression and signaling, and profound anti-tumor activity in vitro and in vivo. As we reported before, the polyclonal anti-HER2 antibody had a synergistic effect with small-molecule
HER2 kinase inhibitors [13]. In addition to antibodies induced by potent adenoviral vectors, we studied HER2specific antibodies induced by a HER2 protein vaccine being tested in clinical trials in breast cancer patients. The HER2-specific antibodies were detected in the serum of vaccinated patients. These human anti-HER2-specific antibodies were capable of binding to surface expressed HER2 and inhibiting HER2 phosphorylation but did not mediate receptor internalization.

\section{Materials and methods Reagents and antibodies}

Vaccine-induced anti-HER2 antibodies (HER2-VIA), LacZ-VIA and GFP-VIA were generated as previously described [13]. Briefly, pooled serum from a large quantity of mice was purified using saturated ammonium sulfate buffer and the concentration of total serum proteins in stock for all of the studies was measured and adjusted to $20 \mathrm{mg} / \mathrm{ml}$ in saline.

Trastuzumab was obtained from the Duke University Medical Center Pharmacy (Durham, NC, USA). Neuregulin was purchased from R\&D systems (Minneapolis, MN, USA). Mouse and rabbit IgG beads were from eBioscience (San Diego, CA, USA). HER2 antibody 3B5 and ubiquitin antibodies were from Santa Cruz Biotechnology (Santa Cruz, CA, USA). HER2 (29D8), HER3, Akt, pAkt, and surviving antibodies were from Cell Signaling (Beverly, MA, USA). Phospho-specific HER2 antibodies (Y877, Y1221/ 1222 and Y1248) were also purchased from Cell Signaling. These antibodies were used at 1:500 dilutions in western blotting.

Lamin B1 rabbit antibody was from Abcam (Cambridge, MA, USA). EZ-Link ${ }^{\mathrm{TM}}$ Sulfo-NHS-SS Biotin and Streptavidin beads were from Pierce (Rockford, IL, USA). $\beta$-actin, $N$-ethylmaleimide, and MG132 were purchased from Sigma (St Louis, MO, USA). Lapatinib was obtained from the Duke University Medical Center Pharmacy.

\section{Treatment of established HER2-positive human tumor xenografts by passive transfer of vaccine-induced antibodies}

These studies were performed under a protocol approved by the Duke University Institutional Animal Care and Use Committee (IACUC) (Durham, NC, USA). Eightweek-old to 10-week-old NOD.CB17-Prkd $c^{\text {scid } / J ~ m i c e ~}$ (Jackson Laboratories, Bar Harbor, ME, USA) were implanted with $17 \beta$-estradiol pellets $(0.72 \mathrm{mg} 60$-day continuous release pellets; Innovative Research of American, Sarasota, FL, USA) in the flank 1 week prior to the implantation of 5 million BT474M1 tumor cells (kindly provided by Mien-Chie Hung, The University of Texas MD Anderson Cancer Center, Houston, TX, USA). Tumors were allowed to develop for 14 days and then mice were randomized to receive intravenous injection of 
either GFP-VIA or HER2-VIA (five mice per group). Then 100 to $150 \mu$ l vaccine-induced antibodies were injected intravenously at 2-day to 3-day intervals for a total of 10 administrations. Tumor growth was measured in two dimensions using calipers, and the tumor volume was determined using the formula:

Volume $=$ width $^{2} \times$ length

The study was terminated on day 39 .

\section{Flow cytometry analysis}

We adapted a methodology reported by Piechocki and colleagues to measure HER2-VIA in vaccinated mouse serum by flow cytometry [14]. Briefly, $3 \times 10^{5}$ HCC1569 cells were incubated with a mouse anti-human-HER2 $\mathrm{mAb}$ or isotype control (Becton Dickinson, San Jose, CA, USA) or with diluted (1:200) mouse serum antibodies (HER2-VIA or LacZ-VIA) for 1 hour at $4^{\circ} \mathrm{C}$ and then washed with $1 \%$ BSA-PBS. The cells exposed to mouse serum containingvaccine-induced antibodies were further stained with phycoerythrin-conjugated anti-mouse IgG (catalogue number R0480; Dako (Carpinteria, CA, USA)) for 30 minutes at $4^{\circ} \mathrm{C}$, and washed again. Samples were then analyzed on a Becton Dickinson LSRII flow cytometer with results represented as histograms.

\section{Cell culture}

HEK293 cells were grown at $37^{\circ} \mathrm{C}, 5 \% \mathrm{CO}_{2}$ in MEM supplemented with $10 \%$ fetal bovine serum (Atlanta Biologicals, Lawrenceville, GA, USA), $200 \mathrm{U} / \mathrm{ml}$ penicillin, and $50 \mathrm{ng} / \mathrm{ml}$ streptomycin (Invitrogen, Carlsbad, CA, USA). SK-BR-3 cells (American Type Culture Collection: HTB$30^{\mathrm{TM}}$ ) were grown at $37^{\circ} \mathrm{C}, 5 \% \mathrm{CO}_{2}$ in McCoy's $5 \mathrm{~A}$ medium supplemented with $10 \% \mathrm{FCS}, 200 \mathrm{U} / \mathrm{ml}$ penicillin, and $50 \mathrm{ng} / \mathrm{ml}$ streptomycin. HCC1569 cells (American Type Culture Collection: CRL-2330 ${ }^{\mathrm{TM}}$ ) were grown at $37^{\circ} \mathrm{C}, 5 \% \mathrm{CO}_{2}$ in $\mathrm{RPM}-1640$ medium also supplemented with $10 \%$ FCS, $1 \mathrm{mM}$ sodium pyruvate, $10 \mathrm{mM}$ Hepes, $0.25 \%$ glucose, $200 \mathrm{U} / \mathrm{ml}$ penicillin, and $50 \mathrm{ng} / \mathrm{ml}$ streptomycin. All cell lines were purchased from American Type Culture Collection (Manassas, VA, USA).

\section{Construction of fluorescent HER2 construct}

HER2-YFP was constructed using a LTR-2/erbB-2(HER2) construct (provided by Dr LE Samelson, NCI, Bethesda, MD, USA) as a PCR template and a pcDNA3.1-mYFP construct as a vector (gift from Roger Y Tsien, University of California at San Diego, USA). HER2 was PCR amplified using the primers 5'-CCCAAGCTTAGCACCATGGAGCTGGCGGCC-3' and 5'-CCGCTCGAGCACTGG CACGTCCAGACCCAG-3', and was inserted into the vector by HindIII and XhoI restriction sites. HER 2 cDNA was verified by sequencing.

\section{Assay of HER2 endocytosis}

Endocytosis of HER2 was assayed using cleavable biotin as described previously [15]. Briefly, SK-BR-3 cells were biotinylated with $1.5 \mathrm{mg} / \mathrm{ml}$ sulfo-NHS-SS-biotin (Pierce) in PBS with calcium and magnesium at $4^{\circ} \mathrm{C}$ for 1 hour. After washing with cold PBS three times, cells were incubated at $37^{\circ} \mathrm{C}$ for 1 hour in McCoy's $5 \mathrm{~A}$ medium with or without antibodies $(50 \mu \mathrm{g} / \mathrm{ml})$ to allow endocytosis to occur. Cell-surface biotin was cleaved by incubation (twice, 15 minutes each) in the glutathione cleavage buffer (50 mM glutathione, $75 \mathrm{mM} \mathrm{NaCl}, 10 \mathrm{mM}$ ethylenediamine tetraacetic acid, 1\% BSA, and $0.075 \mathrm{~N} \mathrm{NaOH}$ ). Cells were washed with PBS three times and scraped into the modified RIPA buffer $(150 \mathrm{mM} \mathrm{NaCl}, 50 \mathrm{mM}$ Tris$\mathrm{HCl}, \mathrm{pH} 7.5,0.25 \%(\mathrm{w} / \mathrm{v})$ deoxycholate, 1\% NP-40, $5 \mathrm{mM}$ sodium orthovanadate, $2 \mathrm{mM}$ sodium fluoride, and a protease inhibitor cocktail). Cell lysates were incubated with streptavidin beads (Pierce) on a rocking platform overnight at $4^{\circ} \mathrm{C}$. After washing, the beads were mixed with the sample buffer and biotinylated proteins were analyzed by immunoblotting using antibodies against HER2.

\section{Western blotting}

The protein samples were subjected to SDS-PAGE using 4-12\% Novex ${ }^{\circledR}$ Tris-Glycine Gels (Invitrogen), transferred to nitrocellulose membranes (Bio-Rad Laboratories, Hercules, CA, USA) blocked with $5 \%$ nonfat milk powder in TBS- $0.2 \%$ Tween-20 for 20 minutes, followed by incubation with primary antibodies and then horseradish peroxidase-conjugated secondary antibodies (Amersham Biosciences, Piscataway, NJ, USA). Imaging and quantification of bands were performed using Supersignal (Pierce Biotechnology, Rockford, IL, USA) and AlphaImager ${ }^{\mathrm{TM}}$ (Alpha Innotech, Santa Clara, CA, USA).

\section{Microscopy}

HEK293 cells plated on 35-mm, poly-D-lysine-coated, glass-bottom microwell dishes (MatTek Cultureware, Ashland, MA, USA) were allowed to grow for 24 hours and transfected (Fugene6; Roche, Indianapolis, IN, USA) with HER2-YFP construct. Twenty-four hours after transfections, the cells were incubated in culture medium for live cell imaging with $100 \mu \mathrm{g} / \mathrm{ml}$ HER2-VIA, LacZ-VIA, trastuzumab, $20 \mathrm{ng} / \mathrm{ml}$ neuregulin or $10 \mathrm{ng} / \mathrm{ml} \mathrm{EGF.} \mathrm{SK-BR-3}$ and HCC1569 cells plated on the dishes were allowed to grow for 24 hours and were treated as above for the indicated time at $37^{\circ} \mathrm{C}$ before fixation in $4 \%$ paraformaldehyde. Fixed cells were permeabilized and blocked in buffer (5\% BSA with $0.2 \%$ saponin in PBS) for 20 minutes at room temperature and washed in PBS. Where indicated, cells were incubated with primary antibody (rabbit monoclonal sc-13584; Santa Cruz) in blocking buffer for 1 hour at room temperature, washed, incubated with secondary 
antibody (Alexa-594-conjugated goat anti-rabbit; Invitrogen) in blocking buffer for 60 minutes at room temperature, washed, and mounted with mounting medium (Vector Laboratories, Inc., Burlingame, CA, USA).

Live cells were studied at $37^{\circ} \mathrm{C}$ using a heated microscope stage. All slides were examined using a LSM 510Meta confocal microscope (Carl Zeiss, Thornwood, NY, USA) equipped with $40 \times$ and $100 \times$ apochromat objectives. YFP was excited using a 488-nm argon laser line. Alexa fluorophores were excited at $543 \mathrm{~nm}$ using a $\mathrm{NeHe}$ laser. Images were processed using the LSM software Image Browser (Carl Zeiss).

\section{Assay of HER2 degradation and ubiquitination}

A total of 0.15 million SK-BR-3 cells or HCC1569 cells plated in six-well plates were allowed to grow for 24 hours in medium with $10 \%$ fetal bovine serum and incubated with $100 \mu \mathrm{g} / \mathrm{ml}$ HER2-VIA, LacZ-VIA and trastuzumab in serum-free medium for the indicated time. Cells were washed twice with PBS and lysed with $2 \times$ SDS sample buffer, and the cell lysates were subjected to western blot analysis. For ubiquitination assays, the cells were cultured as described above and then treated with $10 \mu \mathrm{M}$ MG132 in serum-free medium for 1 hour before incubation with $100 \mu \mathrm{g} / \mathrm{ml}$ HER2-VIA, LacZ-VIA and trastuzumab for the indicated time. After washing twice with PBS, the cells were collected into glycerol lysis buffer (50 mM Hepes, $250 \mathrm{mM} \mathrm{NaCl}, 0.5 \%$ NP40, 10\% glycerol, $2 \mathrm{mM}$ ethylenediamine tetraacetic acid) with $5 \mathrm{mM} \mathrm{N}$-ethylmaleimide and incubated with $25 \mu \mathrm{l}$ mouse and rabbit IgG beads for at least 1 hour. The cell lysate was then spun at 18,000 g for 10 minutes to remove the beads, and the supernatant was incubated overnight with $1 \mu \mathrm{l}$ anti-HER 2 antibody 29D8 (Cell Signaling). This was followed by addition of 25 $\mu \mathrm{l}$ rabbit IgG beads for another 2 hours, washing the mix three times with glycerol lysis buffer, and subsequent western blot analysis.

\section{Patients and treatment/monitoring}

The human clinical trial enrolled patients aged 18 or older with stage IV HER2-overexpressing (HER2 3+ or fluorescence in situ hybridization-positive) breast cancer who had documented disease progression or relapse following at least one prior standard therapy containing trastuzumab [16]. These patients were immunized with dHER2, a recombinant protein consisting of the extracellular domain and a portion of the intracellular domain of HER2 combined with the adjuvant AS15, containing MPL, QS21, CpG and liposome. Lapatinib (1,250 mg/ day) was administered concurrently. Serum was collected at various times pre and post immunization and antibodies were purified from the serum using ammonium sulfate precipitation.

\section{Statistical analysis}

A mixed-effects model was fit to fold-change measurements, with a regression model used to describe the tumor volume by treatment over time. Treatment and mouse were considered categorical variables. Day was considered a continuous variable. Day-squared and the dayxtreatment and day-squared $x$ treatment interactions were also considered. Treatment and day were considered as fixed effects, and volume measurements for each mouse were considered as repeated measures within treatment. Tumor volume was measured on days $8,10,12,14,16,18$, and 20 post inoculation. Covariance was modeled as autoregressive. The likelihood ratio test was highly significant $\left(\chi^{2}=28.27\right.$ with 2 degrees of freedom; $\left.P<0.01\right)$, such that one concludes there is a sharp treatment difference in tumor growth over time.

\section{Results}

\section{Generation of HER2-VIA antibodies against HER2}

We developed adenovirus vectors encoding human HER2/ neu with a kinase-inactivating mutation in order to ablate oncogenicity (K753A) [17-21]. The recombinant adenoviruses expressing HER2 were then injected into C57BL/6 mice for anti-HER2 antibody generation. The resulting HER2-VIA were assessed for activity against the extracellular portion of the receptor by flow cytometry, and significant affinity for HER2 at the cell surface was observed (Figure 1A). Based on the flow cytometric assessment of the relative affinity of HER2-VIA compared with trastuzumab in SK-BR-3 cells, we calculated that HER2-VIA-containing crude serum at $\sim 30 \mu \mathrm{g} / \mathrm{ml}$ concentration had the same binding capacity for HER2 as trastuzumab at $1 \mu \mathrm{g} /$ ml concentration (see Additional file 1). Since the concentration of specific antibodies in crude serum is usually less than $1 \%$ of total serum proteins, the affinity of HER2-VIA for HER2 is similar to, if not higher than, that of trastuzumab. Furthermore, overexpressed HER2 or endogenous HER2 protein in SK-BR-3 cells, but not EGFR protein in HEK293 cells, can be detected by HER2-VIA using western blotting, demonstrating the specificity of HER2-VIA for HER2 recognition (Figure 1B).

\section{Anti-tumor effects of HER2-VIA}

We found that passive immunotherapy with HER2-VIA retards the growth of established HER2-positive human tumor xenografts of BT474M1 cells in vivo. Starting at day 21 post inoculation, the average tumor volume in the HER2-VIA-treated group was significantly reduced when compared with mice treated with control GFPVIA (Figure 2A,B). We also wanted to test the effect of HER2-VIA on tumors expressing HER2 but resistant to trastuzumab and lapatinib. HCC1569 cells are highly resistant to trastuzumab and lapatinib treatment in 


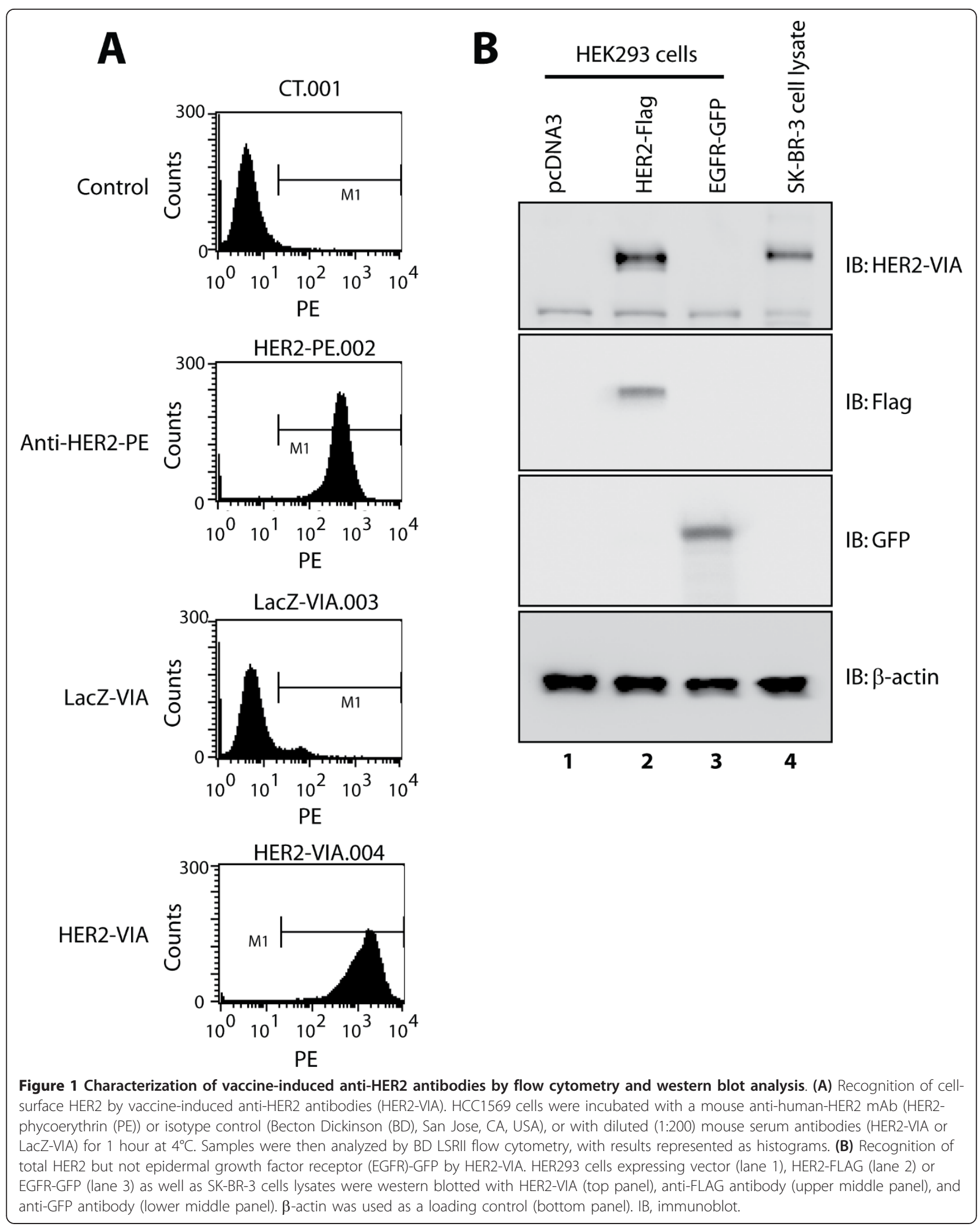




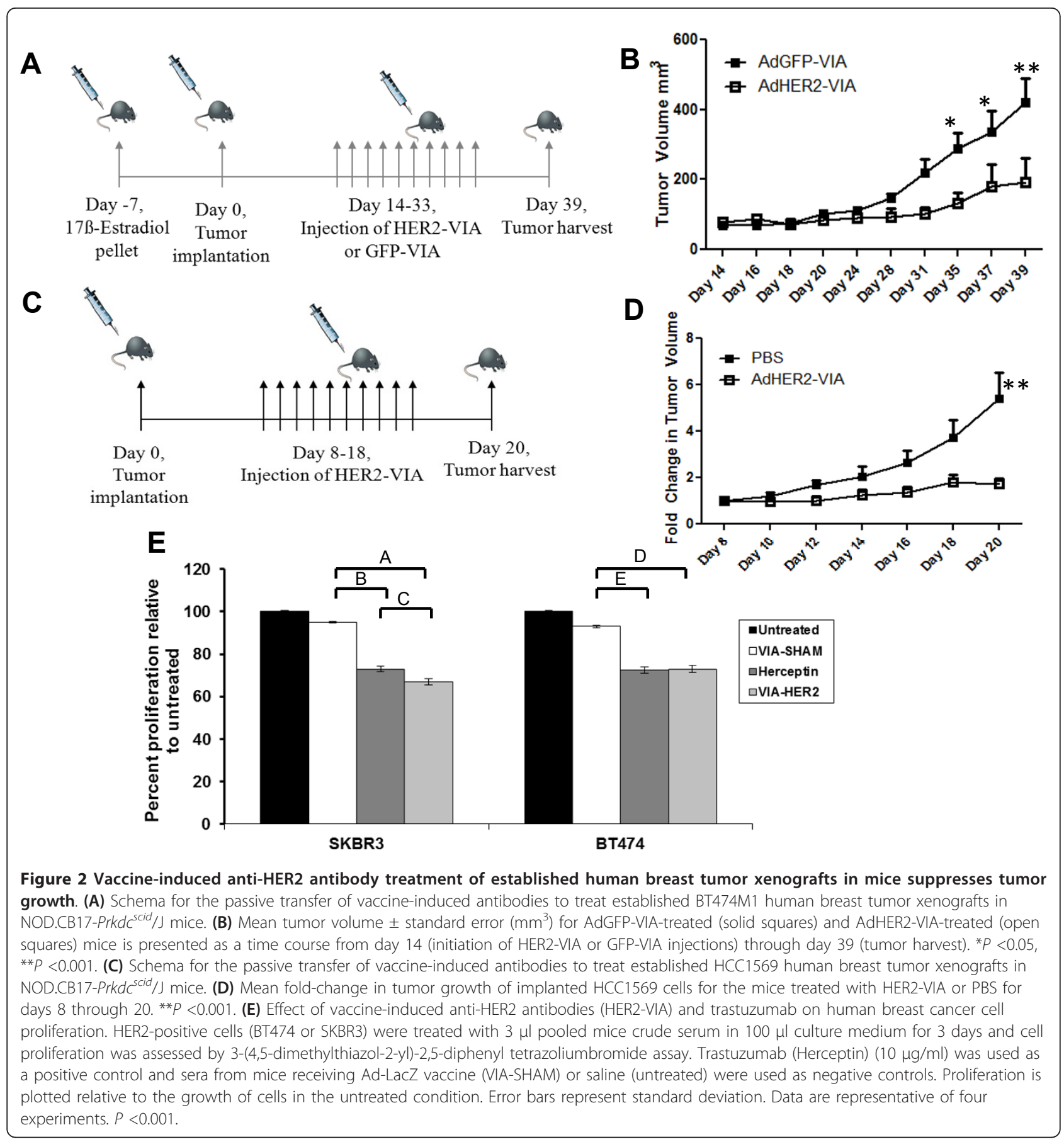

vitro. HER2-VIA was adoptively transferred into HCC1569 tumor-bearing recipient mice and significantly $(P<0.001)$ suppressed tumor growth relative to control treated mice (Figure 2C,D, tumor volume fold-change). Accordingly, HER2-VIA - like trastuzumab - inhibits cell proliferation in breast cancer SK-BR-3 and BT474 cells in vitro, as shown in Figure 2E. However, HER2VIA treatment had little effect on HCC1569 cell proliferation in vitro (data not shown), suggesting that HER2-
VIA functions more effectively against HCC1569 cells in vivo. Future studies are needed to determine whether higher concentrations of HER2-VIA are needed to inhibit HCC1569 cells in vitro. Based on these anti-tumor effects, we hypothesized that the polyclonal HER2 antibodies may have a direct effect on receptor internalization and degradation. We therefore proceeded to study the molecular events following antibody-receptor interaction. 


\section{Activation of HER2 by HER2-VIA}

Despite a lack of identified HER2-soluble ligands, HER2 phosphorylation on multiple tyrosine sites (including residues $877,1,221,1,222$ and 1,248) has been established from HER2 activation by homodimerization or heterodimerization [18,22-24]. In SK-BR-3 breast cancer cells transiently stimulated with HER2-VIA, phosphorylation of HER2 on sites $877,1,221,1,222$ and 1,248, as well as phosphorylation of the downstream HER2 signaling molecules Akt and ERK, was detected (Figure 3, lanes 1 to 5). The HER2 and EGFR tyrosine kinase inhibitor lapatinib abolished tyrosine phosphorylation at these sites, as well as blocking activation of Akt and ERK (Figure 3, lanes 6 to 10). These data indicate that HER2-VIA initially behaves as a HER2 agonist, similar to trastuzumab [25-27].

\section{Internalization of HER2 upon HER2-VIA stimulation}

To characterize the effect of antibodies on HER2 receptor internalization, HEK293 cells transfected with HER2-YFP were incubated with $100 \mu \mathrm{g} / \mathrm{ml}$ HER2-VIA antibody for 1 hour prior to observation. HER2-VIA-induced internalization of HER2-YFP resulted in the formation of fluorescent cytosolic aggregates (Figure 4A, a vs. b). As shown in Additional file 1, $100 \mu \mathrm{g} / \mathrm{ml}$ HER2-VIA antibody exhibits a HER2 fluorescence staining intensity comparable with $5 \mu \mathrm{g} / \mathrm{ml}$ trastuzumab. However, a 20-fold excess of trastuzumab $(100 \mu \mathrm{g} / \mathrm{ml})$ behaved similarly to LacZ-negative control antibody and was unable to internalize receptor, because YFP fluorescence remained at the plasma membrane (Figure 4A, c to 4f).

We next sought to confirm the findings of Figure 4A for endogenous HER2 receptor internalization using breast cancer cell lines SK-BR-3 and HCC1569, which each express abundant HER2 protein but are sensitive or resistant to trastuzumab treatment, respectively [28]. As is shown (Figure 4B, a to 4c), HER2-VIA induced HER2 internalization in SK-BR-3 cells while LacZ control antibody had little to no effect. Trastuzumab produced only a small complement of internalized HER2 receptors in SKBR-3 cells (Figure 4B, d). Similarly, treatment of HCC1569 cells with HER2-VIA caused a significant amount of endogenous HER2 internalization while LacZ-VIA and trastuzumab had no effect (Figure 4B, e to $4 \mathrm{~h}$ ). Counterstaining cells with the nuclear membrane marker lamin $\mathrm{B}$ indicates that the internalized endogenous HER2 localizes exclusively to the cytosol (see Additional file 2), suggesting that HER2 internalization does not lead to HER2 nuclear translocation as reported [29].

We further studied the effect of antibodies on endogenous HER2 receptor endocytosis using a biotin method to label HER2 at the cell surface, as shown in Figure 4C. Western blotting of biotin-labeled internalized receptors that originated at the cell surface demonstrates that HER2-VIA induces robust HER2 internalization (Figure 4C, lane 3 vs. rest of the lanes). Note also that raising the temperature of the cells from 4 to $37^{\circ} \mathrm{C}$ induces a small amount of HER2 internalization (Figure 4C, lanes 1 and 2) [15]. In addition, HER2 internalization induced by HER2-VIA is tyrosine kinase independent, because it occurs in the presence of the kinase inhibitor lapatinib (Figure 4D,E).

\section{Internalization of HER2 through clathrin-coated pits/ vesicles}

Upon EGF stimulation, HER1 (EGFR) undergoes internalization through clathrin-coated pits/vesicles where it co-internalizes with HER2 [30-32]. To elucidate the HER2 internalization process, we examined the capacity of HER2-VIA to modulate trafficking of heterodimers of EGFR and HER2 (Figure 5A). GFP protein was fused to the C-terminus of EGFR (EGFR-GFP) and RFP protein was fused to the $C$ terminus of HER2 (HER2-RFP). In addition to membrane localization, a small percentage of the EGR receptors were localized to the cytoplasm basally when co-expressed with HER2 in HEK293 cells (Figure 5A, a, g and $5 \mathrm{~m}$ ). This is probably due to the constitutive endocytosis and recycling of EGFRs that is known to be ligand independent [33,34]. HER2-VIA treatment of HEK293 cells transiently co-expressing HER1-GFP (EGFR-GFP) and HER2-RFP caused robust HER2-RFP internalization (Figure 5A, a to 5f). However, the overall distribution and the membrane localized EGFR were not altered by the HER2-VIA treatment, suggesting that the HER2-VIA-induced endocytosis is specific for HER2 (Figure 5A, d). In contrast, EGF ligand treatment caused robust EGFR-GFP internalization but had little or no effect on HER2 distribution (Figure 5A, $\mathrm{g}$ to $5 \mathrm{l})$. When cells were treated simultaneously with HER2-VIA and EGF, internalization of both HER2 and EGFR was observed and the two markers extensively overlapped within the cells (Figure 5A, m to $5 \mathrm{r}$ ). These data are also suggestive of HER2 utilizing the same clathrin mechanism for receptor internalization as EGFR [10].

$\beta_{2}$-adrenergic receptors are prototypical for clathrindependent internalization of G-protein-coupled receptors $[35,36]$, and transferrin is a well-documented standard for clathrin-mediated internalization in general [37]. The demonstration that internalized HER2-YFP co-localizes with either $\beta_{2}$-adrenergic receptor-RFP or transferrin in intracellular vesicles would further confirm that HER2 also internalizes in manner similar to these other proteins. As shown in Figure $5 \mathrm{~B}$, in cells expressing both $\beta_{2^{-}}$ adrenergic receptor-RFP and HER2-YFP receptors and prior to activation, the two receptors are not intracellularly co-localized (Figure 5B, a to 5c). Exposure to isoproterenol and HER2-VIA for 1 hour resulted in multiple overlapping intracellular distributions of these receptors (Figure 5B, d to 5f). Similarly, internalized transferrin at 1 


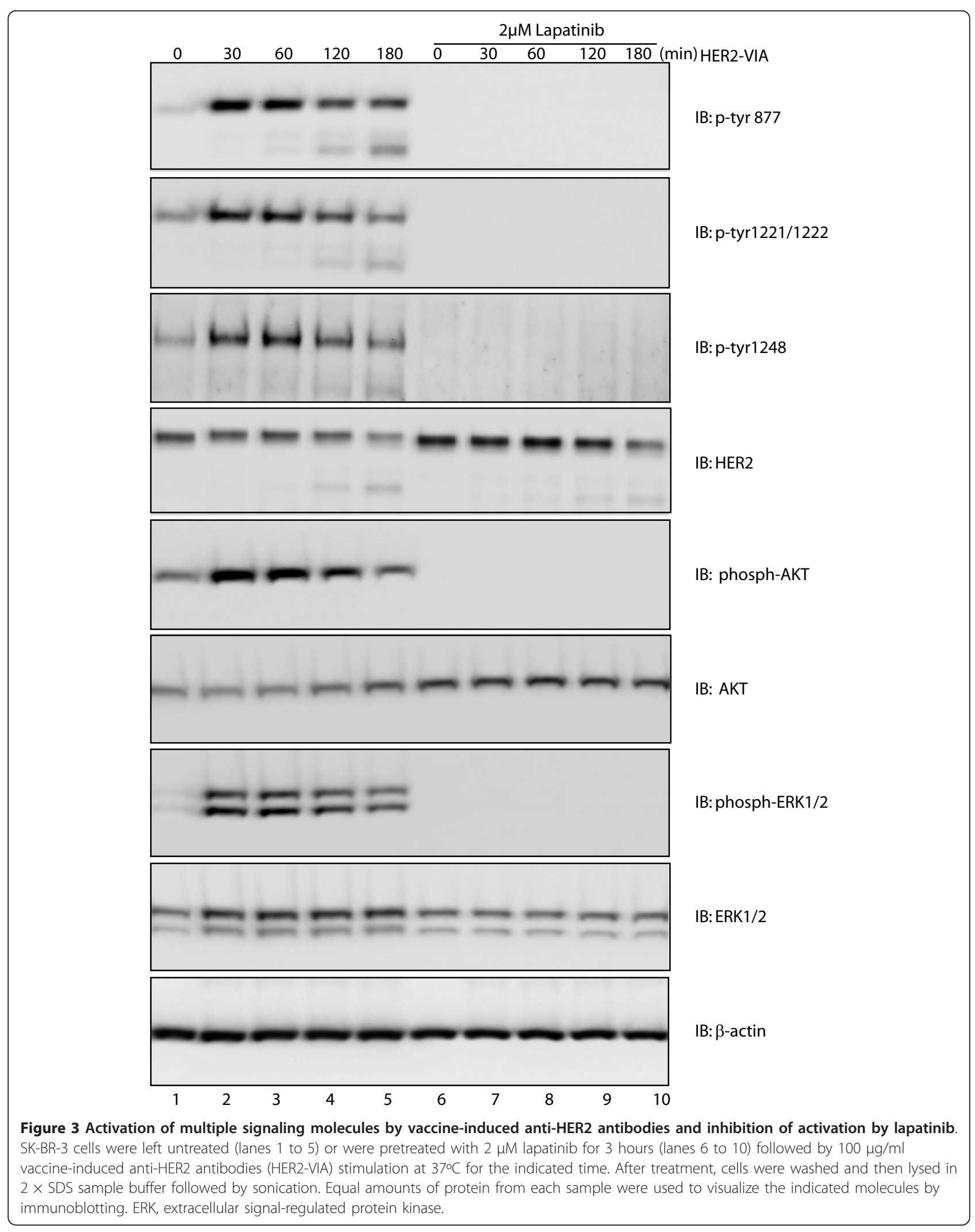


A

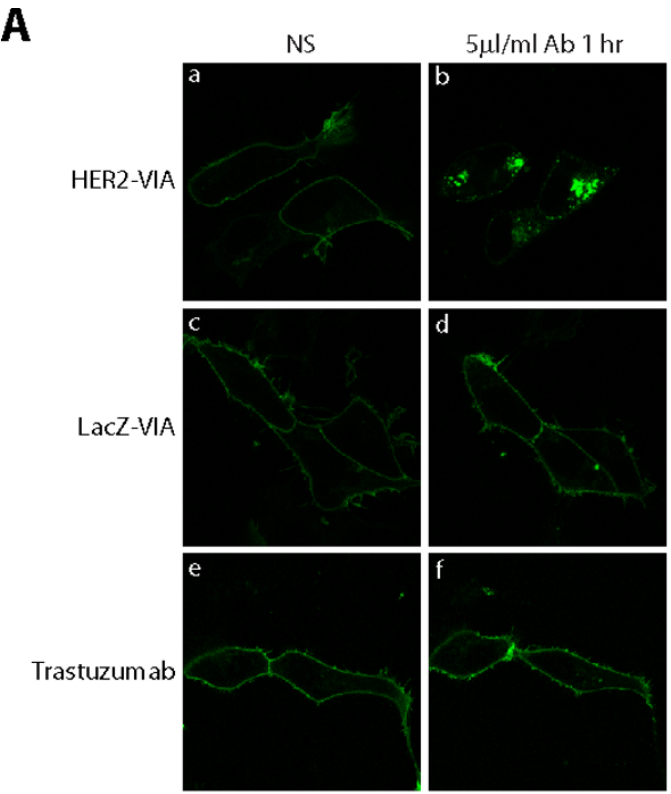

C

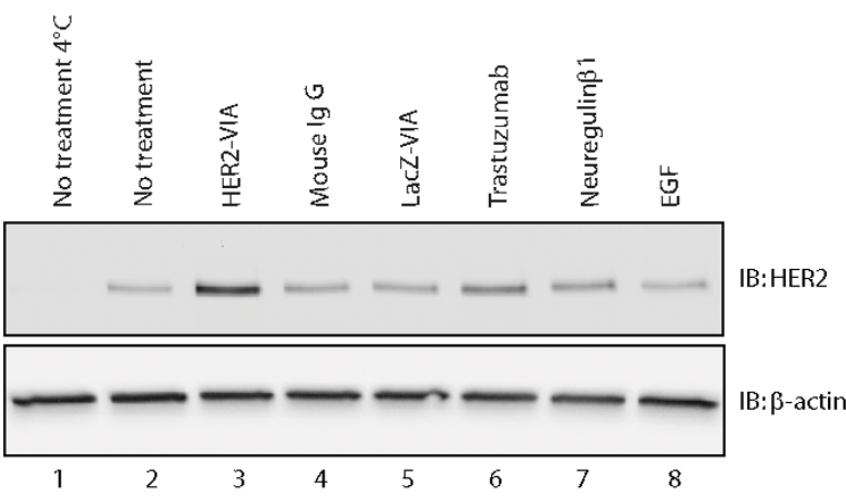

D
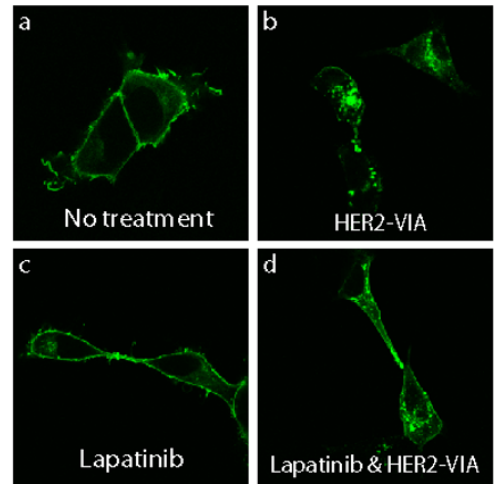

B
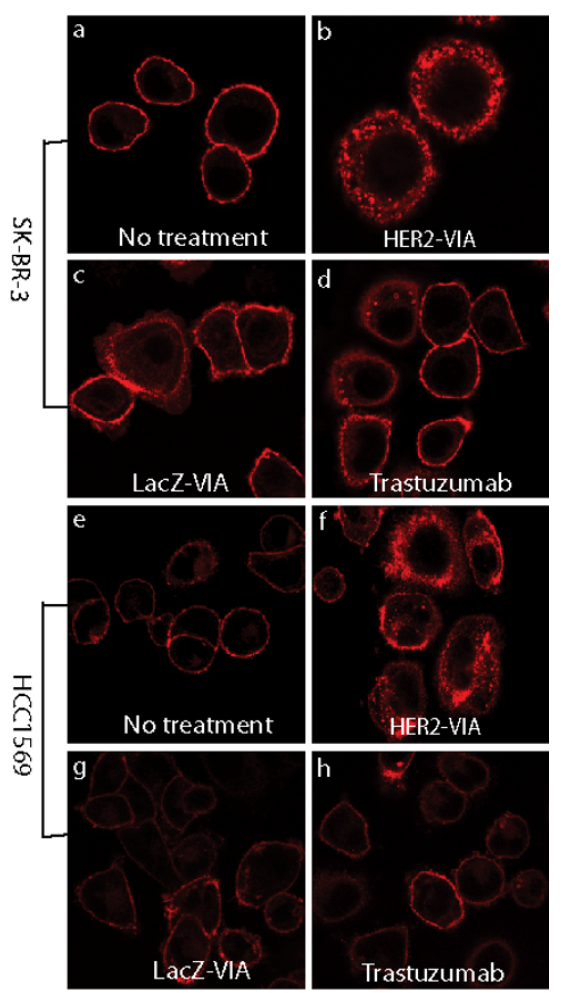

$\mathbf{E}$

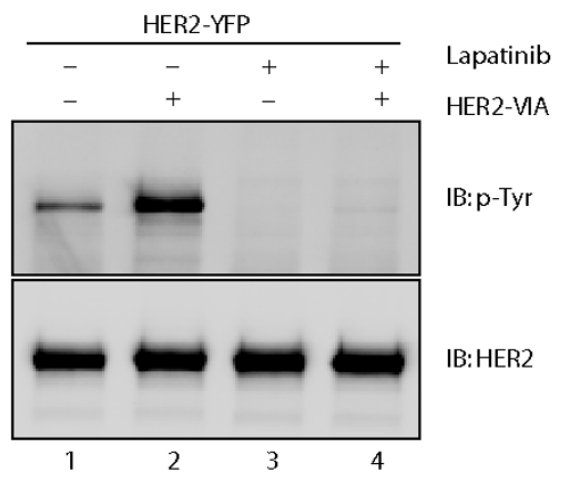

Figure 4 Effects of vaccine-induced anti-HER2 antibodies on HER2 internalization. (A) Internalization of HER2-YFP by vaccine-induced anti-HER2 antibodies (HER2-VIA). HEK 293 cells transiently expressing HER2-YFP were stimulated with (a, b) HER2-VIA, (c, d) LacZ-VIA, or (e, f) trastuzumab, respectively for 1 hour. Confocal images from the same cells were taken before and after antibody incubation. Formation of vesicles in the cells indicated receptor internalization. The experiment was repeated three times. NS, non-stimulated. (B). Imaging endogenous HER2 internalization by HER2-VIA. SK-BR-3 and HCC1569 cells were allowed to grow for 24 hours and were treated as described in Materials and methods. Confocal images of cells that (a, e) were left untreated, or were treated with (b, f) HER2-VIA, (c, $\mathbf{g})$ LacZ-VIA or (d, $\mathbf{h})$ trastuzumab. (C) Endogenous HER2 internalization by HER2-VIA as assessed by cell surface Biotin-labeling. Upper panel: immunoblot (IB) for protected (internalized) biotin-labeled HER2 in cells treated with indicated agents/conditions. Lower panel: $\beta$-actin serves as loading control to ensure equal amounts of cell lysate. EGF, epidermal growth factor. (D) Effect of lapatinib on HER2-YFP internalization induced by HER2-VIA. Confocal images of HEK293 cells expressing HER2-YFP that (a) were left untreated, or were treated with (b) HER2-VIA, (c) lapatinib or (d) lapatinib then HER2-VIA for 1 hour. (E) The same transfected cells were immunoblotted (IB) for HER2 tyrosine phosphorylation (upper panel) and total HER2 expression (lower panel). 


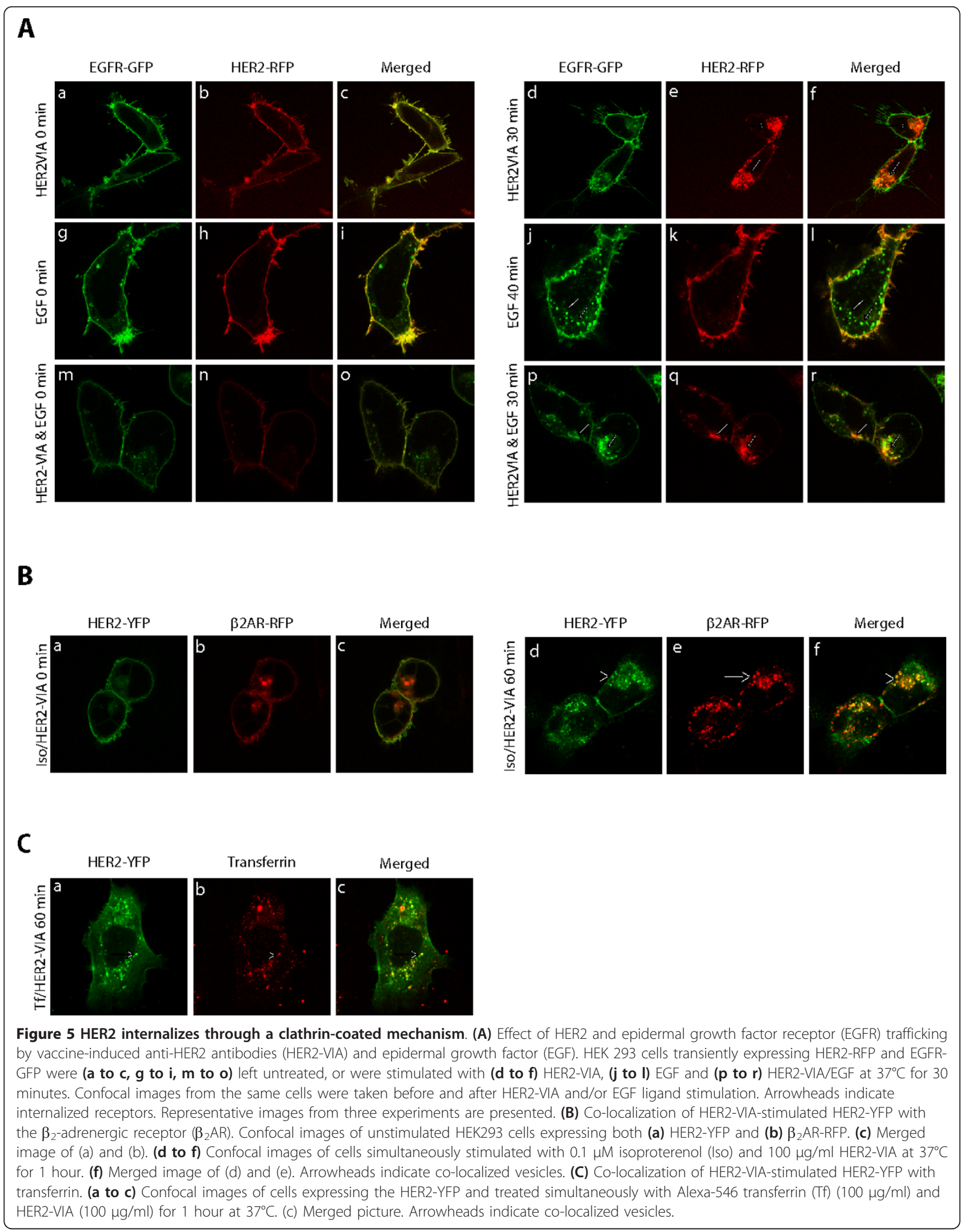


hour has significant co-localization with internalized HER2-YFP (Figure 5C). To further demonstrate that HER2-VIA-induced HER2 internalization occurs through clathrin-coated pits, SK-BR-3 cells were treated with sucrose, a known inhibitor of clathrin-dependent endocytosis [38]. As shown in Additional file 3, HER2-VIAinduced internalization of HER2 was effectively blocked by sucrose, and this inhibition was reversible because removing sucrose from the cells allowed the internalization of HER2 to proceed. Taken together, these data suggest that HER2-VIA-induced HER2 internalization occurs through a clathrin-coated pit mechanism.

\section{Ubiquitination of HER2 upon HER2-VIA stimulation}

Receptor internalization is often associated with receptor ubiquitination and targeting to proteasomes for degradation. In SK-BR-3 cells transiently expressing exogenous Myc-tagged ubiquitin, HER2-VIA treatment resulted in increased HER2-ubiquitin-Myc in the presence of $10 \mu \mathrm{M}$ of the protease inhibitor MG132, as assessed by western blotting (Figure 6A). HER2-VIA also led to ubiquitination of endogenous HER2 receptor in SK-BR-3 cells in the presence of MG132 (Figure 6B). Interestingly, we found that the ubiquitination of HER2 induced by HER2VIA treatment was effectively blocked by $1 \mu \mathrm{M}$ lapatinib (see Additional file 4). It has also been shown previously that lapatinib is capable of stabilizing HER2 proteins by inhibiting basal-induced and trastuzumab-induced ubiquitination of HER2 [26]. Our results are consistent with the notion that HER-VIA functions by activating HER2 receptors and subsequently triggers internalization and ubiquitination.

\section{Degradation of HER2 upon HER2-VIA stimulation}

To explore the stability of HER2 after internalization, SKBR-3 cells were incubated with HER2-VIA and harvested. Using western blot analysis we demonstrated that HER2VIA treatment for 3 hours induced a significant reduction of total HER2 (Figure 6C). A 9-hour treatment reduced HER2 protein expression by about $70 \%$. In contrast, the amount of HER2 protein did not decrease after treatment with control antibody LacZ-VIA. Trastuzumab also did not reduce HER2 protein expression (Figure 6C). Similar results were obtained in HCC1569 cells (Figure 6D), suggesting that HER2-VIA is an effective antibody for promoting HER2 degradation.

\section{Truncation of HER2 upon HER2-VIA stimulation}

HER2 is a 1,255-amino-acid protein that migrates at $185 \mathrm{kDa}$. Similar to other EGF family receptors, the extracellular domain of HER2 can be cleaved, reportedly at amino acid site R647, A644 or N530 [39]. Following HER2-VIA stimulation we observed the formation of a $130 \mathrm{kDa}$ fragment of HER2 that was associated with a reduction in full-length HER2 expression (Figure 6E). Blockade of proteasome digestion prevented the appearance of this cleaved form of HER2 (Figure 6E). Moreover, this fragment was phosphorylated at tyrosine residues (referenced to full-length HER2) 877, 1,221, 1,222 and 1,248 as detected by phospho-specific antibodies (Figure 6F, lanes 1 and 2). Since tyrosine 1,248 is present in this $130 \mathrm{kDa}$ fragment, the cleavage must take place at the amino-terminal end of HER2. Lapatinib treatment had no effect on the appearance of the $130 \mathrm{kDa}$ fragment (Figure 6F, lanes 3 and 4) while the protease inhibitor MG132 blocked its formation (Figure 6F, lanes 5 and 6). However, HER2-VIA-induced tyrosine phosphorylation of the fragment was abolished with lapatinib treatment (Figure 6F, lanes 3 and 4). Taken together, these data suggest that this $130 \mathrm{kDa}$ fragment is cleaved from the HER2 $\mathrm{N}$-terminus and may represent a novel cleavage site, distinct from those observed previously [40] (Figure 6E).

\section{Reduced signaling by HER2 following prolonged-HER2- VIA treatment}

In SK-BR-3 breast cancer cells transiently exposed to HER2-VIA, phosphorylation of HER2 on sites 877, 1,221, 1,222 , and 1,248 as well as phosphorylation of the downstream HER2 signaling molecules AKT and ERK was detected (Figure 3, lanes 1 to 5). However, prolonged HER2-VIA binding (up to 72 hours stimulation) resulted in decreased AKT phosphorylation, probably due to the decreased HER2 expression after prolonged treatment (Figure 7A,B).

\section{Effects of human HER2-specific antibodies}

As an extension of the above experiments, we were interested in studying the signaling effects of human antibodies generated against HER2 in the setting of tyrosine kinase inhibition, Prior to utilizing our recombinant viral vectors expressing HER2 with lapatinib in humans, important safety issues regarding combination HER2-specific vaccination and kinase inhibition needed assessment. We therefore proceeded to study the concept of vaccination with concomitant kinase inhibition using a HER2 protein vaccine (dHER2) that was in clinical trial development in combination with lapatinib for this first study in humans. The vaccine we proposed to test, dHER2, consists of the extracellular domain and part of the intracellular domain of HER2 combined with the adjuvant AS15 containing MPL, QS21, CpG and liposome.

In this study, women with metastatic, trastuzumabrefractory HER2-overexpressing breast cancer were immunized six times at 2-week intervals with dHER2 concomitantly with oral lapatinib $(1,250 \mathrm{mg} /$ day $)$. The clinical results and primary immune analysis of this study are reported elsewhere [16]. The specificity of human serum samples against HER2 receptors has been verified 


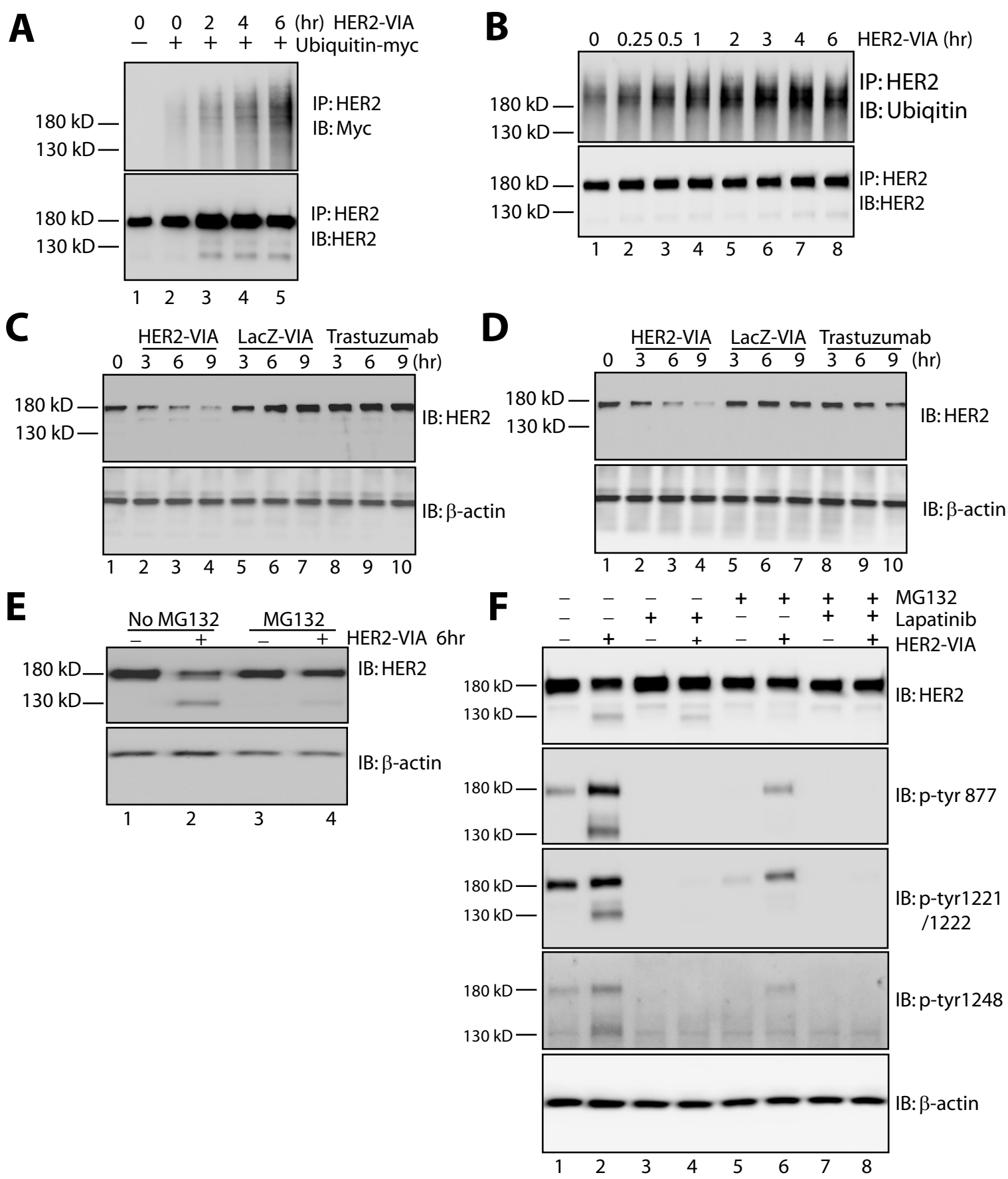

Figure 6 HER2 ubiquitination, degradation, and fragmentation induced by vaccine-induced anti-HER2 antibodies. (A) Vaccine-induced anti-HER2 antibodies (HER2-VIA) stimulation led to HER2 ubiquitination. SK-BR-3 cells expressing ubiquitin-Myc were pretreated with MG132 for 2 hours and then treated with HER2-VIA for the indicated time. The ubiquitinated HER2 was detected by anti-Myc antibody. (B) HER2-VIA stimulation leads to HER2 ubiquitination. SK-BR-3 cells were pretreated with MG132 for 2 hours before HER2-VIA stimulation. Cell lysates were immunoprecipitated with anti-HER2 29D8 antibody. The endogenous ubiquitinated HER2 was detected by the anti-ubiquitin antibody and the total HER2 was visualized by anti-HER2 3B5 antibody. (C), (D) HER2-VIA stimulation causes HER2 degradation: (C) SK-BR-3 and (D) HCC1569 cells were stimulated with HER2-VIA, LacZ-VIA, or trastuzumab for the indicated time, and an equal amount of cell lysates was subjected to western blot analysis. Expression levels of HER2 and $\beta$-actin were detected by corresponding antibodies. (E) HER2-VIA stimulation produces HER2 fragmentation. SK-BR-3 cells were treated with HER2-VIA for 6 hours in the absence or presence of prior MG132 treatment for 2 hours. Fulllength and truncated HER2 are detected by anti-HER2 3 B5 antibody. $\beta$-actin serves as loading control. (F) HER2-VIA stimulation produces tyrosine phosphorylation of the $130 \mathrm{kDa}$ HER2 C-terminal fragment. SK-BR-3 cells were incubated with HER2-VIA for 6 hours after pretreatment with lapatinib, MG132, or lapatinib plus MG132 for 2 hours. Full-length and truncated HER2 are detected by anti-HER2 3 B5 antibody, which recognizes the C-terminus (top panel). Phosphorylated full-length and truncated HER2 were recognized by tyrosine site-specific phospho-antibodies for phosphorylated tyrosine 877, 1,221/1,222 and 1,248 (middle three panels). IB, immunoblot. 


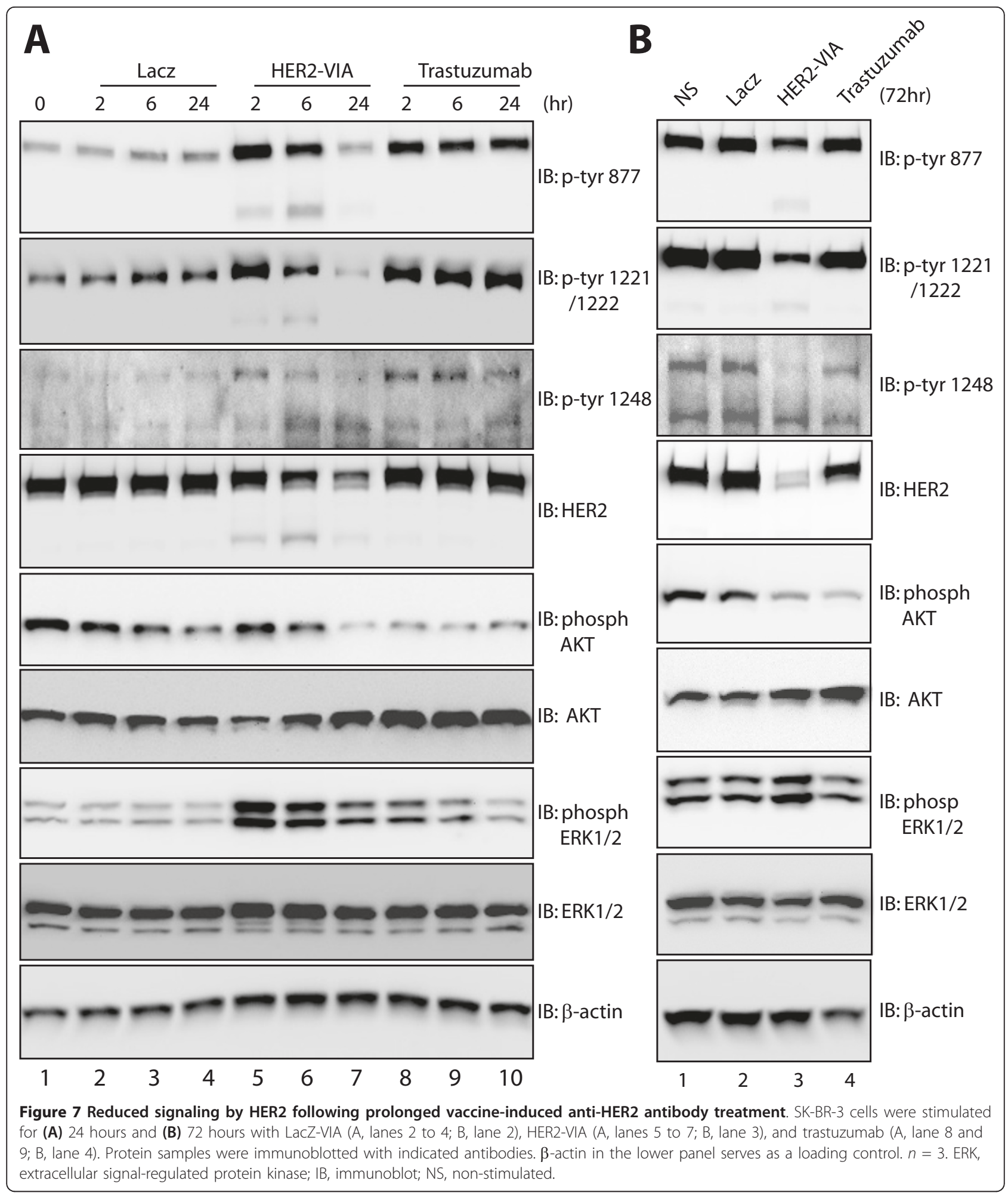

using ELISAs as described in the previous study [16]. To further determine the molecular mechanism of human HER2 antibodies, crude serum antibodies from three patients with the highest titer of antibodies to the HER2 extracellular domain were obtained via ammonium sulfate precipitation to deplete lapatinib and then tested for binding to HER2-expressing cells. Although human HER2 antibodies are capable of binding to HER2 as 
shown previously [16], no receptor internalization was observed after 1 hour of incubation in contrast to the rapid receptor internalization and degradation noted with the murine HER2-VIA (Figure 8A). Even after 6 hours of treatment, no HER2 internalization was observed in SK-BR-3 cells incubated with human antibodies (data not shown). Nonetheless, phosphorylation of HER2 (tyrosine 877 ) was markedly decreased by patients' serum upon 6 hours of treatment (Figure 8B); meanwhile, the phosphorylation of HER2 (tyrosine 877) remained relatively unchanged upon short-term stimulation of SKBR-3 with patient antibodies, unlike murine HER2-VIA, which possesses agonistic effect on HER2 signaling (see Additional file 5).

In summary, our studies suggest that HER2-VIA antibodies possess some properties characteristic of agonists, such as promoting HER2 signaling, but that this is soon followed by receptor internalization, ubiquitination and, finally, degradation and downregulation of signaling.

\section{Discussion}

Constitutive HER2 internalization and membrane recycling normally occur at a very slow rate in many cell systems in the absence of a recognized agonist. A recent report indicates that one $\mathrm{mAb}$ or multiple $\mathrm{mAbs}$ against HER2, alone or in combination, were able to induce HER2 internalization over intervals as short as 4 hours, but the mechanisms underlying the internalization were not determined [41]. Interestingly, even slow HER2 internalization is associated with reductions in HER2 signaling and decreases in tumor growth rates. We found that polyclonal anti-HER2 antibodies were remarkably more potent than the mAb trastuzumab in causing HER2 internalization and degradation. Our data indicate that HER2-VIA antibodies are HER2 agonists that bind and internalize the receptor, signal through ERK1/2 and Akt, and deplete HER2 from the plasma membrane by the same clathrin-mediated mechanisms utilized by other HER family members exposed to cognate agonists.

Although polyclonal antibodies specific to HER2 are not clinically available, active immunotherapy targeting tumor antigens can lead to tumor antigen-specific immune responses. We have administered HER2 protein-loaded autologous dendritic cells to patients with advanced HER2-overexpressing tumors. Remarkably, we found that all patients were long-term survivors, and six out of seven patients had developed HER2-specific antibodies that inhibited tumor growth in vitro [13]. Alternatives to autologous dendritic cell vaccines include tumor antigen-expressing recombinant vectors. We have developed a potent novel recombinant vector expressing kinase-inactivated HER2 that induced high levels of HER2-specific antibodies [17], and vaccination with this vaccine demonstrated synergy when combined with HER2 kinase inhibition with lapatinib [13], consistent with clinical observations that combinations of antibodies and small-molecule tyrosine kinase inhibitor are more effective than monotherapy.

The HER2-VIA binding sites that are both necessary and sufficient for rapid HER2 removal from the plasma membrane remain unidentified, but these sites could become future targets for small molecules or could be important to elucidation of structure-activity relationships. Other agents are known to produce HER2 internalization but with slower kinetics, suggesting that allosteric modulation of receptor conformation may be sufficient to achieve desired therapeutic goals in the absence of an identified HER2 agonist. Exposure of cells to the ansamysin antibiotic geldanamycin results in HER2 degradation with cleavage of a $130 \mathrm{kDa} C$-terminus fragment, the separation of HER2 from Hsp90, and within 2 hours the accumulation of HER2 in cytoplasmic vesicles [40]. It is unclear whether the vesicular compartmentalization of HER2 is a consequence of enhanced receptor internalization or an inhibition of receptor recycling, but recent evidence points to the latter. It also has not been determined whether geldanamycin leads to HER2 activation or whether HER2 trafficking is clathrin dependent or independent, asboth explanations have been proposed [42-44].

Interestingly, our western blotting data indicate that the majority of HER2 receptors remain intact following HER2-VIA treatment. However, in contrast to geldanamycin treatment, a $130 \mathrm{kDa}$ fragment truncated at the $\mathrm{N}$-terminus of HER2 is observed in cells that are treated with HER2-VIA, while mAb treatment does not produce a similar fragment. Moreover, we show that HER2-VIAinduced internalization of HER2 receptors precedes HER2 degradation. The internalized HER2-containing vesicles (observed in Figure 4A, b) may represent the receptors localized in the endosome compartment, where the receptors are waiting to be further sorted and can still signal. The level of HER2 remains relatively unchanged until the receptors traffic to the lysosome at a later time point where the protein degradation occurs. Our finding is consistent with a recent study showing that geldanamycin-induced HER2 internalization can be observed within 2 hours whereas the degradation of HER2 did not occur until 6 hours after the treatment [45]. The half-life of HER2 in HER2-VIA-treated cells is around 3 hours, which is similar to that observed in geldanamycin-treated cells [40]. Interestingly, the time course of Akt dephosphorylation tightly correlates with the time course of HER2-VIA-induced dephosphorylation and degradation of HER2. In HER2-overexpressing cells such as SK-BR-3, the termination of downstream signaling probably only occurs after the level of HER2 is 


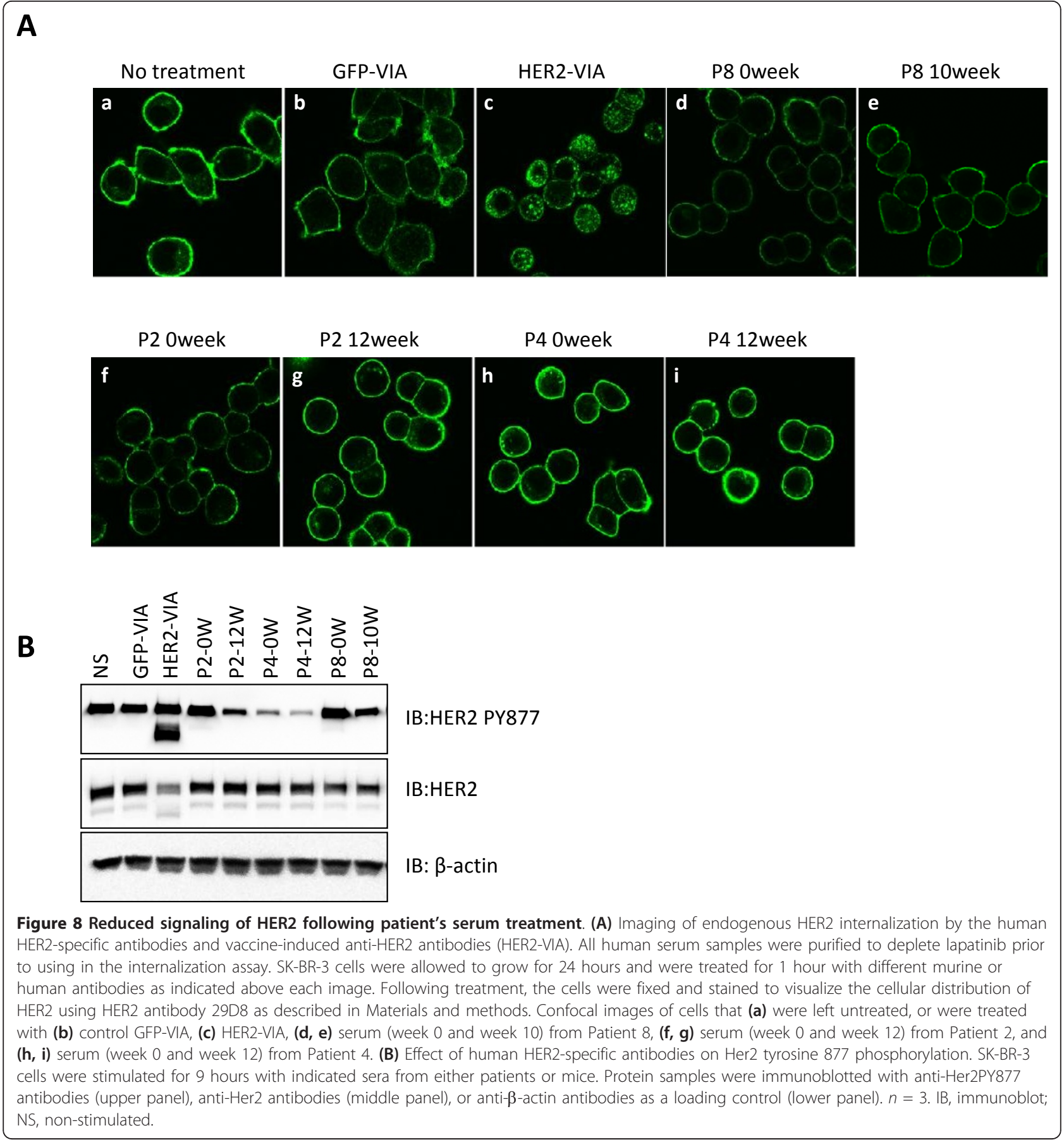

reduced substantially. Taken together, our findings indicate that although HER2-VIA shares certain similarities with trastuzumab and geldanamycin in its ability to inhibit HER signaling, it affects HER2 behavior in a manner quite distinct from either trastuzumab or geldanamycin.

The responses we observed with polyclonal anti-HER2 antibodies suggest that their mechanism of action may underlie new strategies for cancer immunotherapy. Most active immunotherapy strategies have not resulted in large clinical reductions of tumors. Nonetheless, recent reports have suggested that, despite the absence of classical clinical responses to active immunotherapy, there have been long-term survival benefits [46,47]. We anticipated that the generation of HER2-specific antibodies in patients with breast cancer would have similar effects to the murine HER2-specific antibodies. While we were preparing our recombinant HER2-expressing adenoviral vaccine for human testing, we performed a pilot study 
of vaccination of breast cancer patients with a combination of HER2 protein vaccine and lapatinib. Although this vaccine induced detectable HER2-specific antibodies that could recognize HER2 expressed on the surface of tumor cells, we did not see receptor internalization and degradation. We were able to document that the antibodies had an inhibitory effect on HER2 signaling in vitro, as had been previously reported with peptide-based vaccines. Nonetheless, more potent vaccines targeting HER2 may be capable of generating higher-titer HER2specific antibodies, and antibodies that not only bind but mediate receptor internalization and degradation, and the resultant loss of HER2 signaling.

Our studies provide new insights into the mechanisms underlying HER2 receptor trafficking and provide proofof-principle that HER2 can be rapidly removed from the cell surface by agonist-like mimetics that have agonist effects. The absence of HER2 agonists has impeded development of therapies that exploit the relationship between plasma membrane HER2 expression and inappropriate HER2 signaling, but our findings suggest a long-term clinical benefit from oncogenic signaling ablation. Our results with HER2-VIA provide a basis for developing new classes of HER2 signaling inhibitors for patients that are resistant to current modes of therapy. These data also support the clinical evaluation of cancer vaccine strategies targeting HER2, with overall survival rather than tumor shrinkage/progression-free survival as an endpoint.

\section{Conclusions}

We have found that polyclonal anti-HER2 antibodies (HER2-VIA) generated by vaccinating mice with an adenovirus expressing human HER2 can retard the growth of established HER2-positive human tumor xenografts in vivo, bind to HER2 at the plasma membrane, induce HER2 internalization, ubiquitination and degradation, and eventually inactivate downstream kinase Akt. We have also demonstrated that low-titer HER2-specific antibodies induced by vaccinating breast cancer patients with a HER2 protein vaccine can bind to receptor and inhibit HER2 signaling through blocking tyrosine 877 phosphorylation of HER2, but did not induce receptor internalization and degradation. These data support the testing of more potent HER2-specific vaccines in human clinical trials.

\section{Additional material}

Additional file 1: Figure S1 showing flow cytometric assessment of the relative HER2-VIA and trastuzumab binding intensity to HER2-positive SKBR-3 human breast tumor cells. SK-BR-3 cells were incubated with the indicated dilution of (A) HER2-VIA $(1: 100$ to $1: 102,400)$ or (B) trastuzumab ( 20 to $0.02 \mu \mathrm{g} / \mathrm{ml}$ ) and then stained with the appropriate phycoerythrinconjugated anti-lgG secondary antibody. Mean fluorescence intensity, as a measure of antibody binding to HER2, was plotted. LacZ-VIA as a negative control showed an MFI (mean fluorescence intensity) of less than 50 at all dilutions (1:100 to 1:102,400) (data not shown).

Additional file 2: Figure S2 showing HER2-VIA drives HER internalization to the cytoplasm but not to the nucleus. Confocal images of SK-BR-3 cells were (a to $\mathbf{c}$ ) left untreated, or ( $\mathbf{d}$ to $\mathbf{f}$ ) treated with HER2-VIA for 60 minutes. Cells were stained with anti-HER2 antibody $(a, d)$ and lamin B (b, e). (c, f) Merged pictures.

Additional file 3: Figure S3 showing sucrose inhibits HER2-VIA-induced internalization of HER2. SK-BR-3 cells were treated with $20 \mu \mathrm{H}$ HER2-VIA and then incubated with FITC 488-conjugated goat anti-mouse antibody on ice. The cells were then exposed to the following conditions and were then imaged by confocal microscopy: (a) incubation on ice for 1 hour; (b) incubation at $37^{\circ} \mathrm{C}$ for 1 hour; (c) incubation in $0.45 \mathrm{M}$ sucrose on ice; (d) incubation in $0.45 \mathrm{M}$ sucrose at $37^{\circ} \mathrm{C}$ for 1 hour; (e) incubation in $0.45 \mathrm{M}$ sucrose on ice for 30 minutes followed by washing and then incubation of the cells at $37^{\circ} \mathrm{C}$ for 1 hour.

Additional file 4: Figure S4 showing inhibition of HER2-VIA-induced HER2 ubiquitination by lapatinib. SK-BR-3 cells were pretreated with the proteasome inhibitor MG132 (10 $\mu \mathrm{M})$ and lapatinib for 30 minutes before HER2-VIA application for 2 hours. After the indicated treatment, cells were lysed and HER2 was precipitated using anti-HER2 rabbit antibody 29D8. Precipitated proteins were subjected to western blot analysis. Upper panel: ubiquitinated HER2; lower panel: total HER2 visualized by anti-HER2 rabbit antibody 2908.

Additional file 5: Figure S5 showing the effect of human HER2specific antibodies on HER2 tyrosine $\mathbf{8 7 7}$ phosphorylation. SK-BR-3 cells were stimulated for 1 hour with the indicated sera from either patients or mice. Protein samples were immunoblotted with anti-HER2 PY877 antibodies (upper panel) or anti-HER2 antibodies (lower panel).

\section{Abbreviations}

BSA, bovine serum albumin; EGF, epidermal growth factor; EGFR, epidermal growth factor receptor; ERK, extracellular signal-regulated protein kinase; FCS, fetal calf serum; GFP, green fluorescent protein; HER, human epidermal growth factor receptor; HER2-VIA, vaccine-induced anti-HER2 antibodies; mAb, monoclonal antibody; MEM, modified Eagle's medium; PBS, phosphate-buffered saline; PCR, polymerase chain reaction; RFP, red fluorescence protein; YFP, yellow fluorescent protein.

\section{Acknowledgements}

The authors thank Dr Richard Premont for critical reading. This project was supported in part by 1-P01-CA78673-05A1 (to HKL), National Institutes of Health Grant 5R01CA113656-03 (to WC) and Suzan G. Komen Foundation (to HKL and WC) and GlaxoSmithKline Biologicals. WC is a V Foundation Scholar and an American Cancer Society Scholar.

\section{Author details}

'Department of Medicine, Duke University Medical Center, 595 Lasalle Street, Durham, NC 27710, USA. ${ }^{2}$ Duke Comprehensive Cancer Center, Duke University Medical Center, 203 Research Drive, Durham, NC 27710, USA. ${ }^{3}$ Division of Medical Oncology, Department of Medicine, Duke University Medical Center, 203 Research Drive, Durham, NC 27710, USA. ${ }^{4}$ Department of Cell Biology, Duke University Medical Center, 171 Research Drive, Durham, NC 27710, USA. ${ }^{5}$ GlaxoSmithKline Biologicals S.A, 1330 Rixensart, Belgium. ${ }^{6}$ Department of Medicine, Oncology, Duke University Medical Center, 40 Duke Medicine Circle, Durham, NC 27710, USA. Division of General Surgery, Department of Surgery, Duke Comprehensive Cancer Center, Duke University Medical Center, 203 Research Drive, Durham, NC 27710, USA.

\section{Authors' contributions}

$X$-RR participated in the design and coordination of the study, data acquisition and analysis, and helped draft the manuscript. JuW participated in the data acquisition and analysis. GL participated in the data acquisition and analysis. JiW participated in the coordination of the study and helped draft the manuscript. $J$ p participated in the coordination of the study and helped draft the manuscript. WX participated in the design of the study and 
helped draft the manuscript. NS participated in the design of the study and helped draft the manuscript. LB participated in the design of the study and helped draft the manuscript. TC participated in the design of the study and helped draft the manuscript. TO helped with manuscript revision. EH participated in the design of the study, participated in the recruitment of patients, managed specimen acquisition and preparation from the human study, and helped draft the manuscript. KB participated in the recruitment of patients and helped draft the manuscript. AH participated in the coordination of the study, immune analysis of human specimens, and helped draft the manuscript. MAM participated in the design the study, managed specimen acquisition and preparation from the human study and helped draft the manuscript. HKL participated in the design and coordination of the study, and help draft the manuscript. WC participated in the overall design and coordination of the study and drafted the manuscript. All authors gave final approval of the manuscript for publication.

\section{Competing interests}

$\mathrm{EH}, \mathrm{KB}, \mathrm{AH}, \mathrm{NS}, \mathrm{HKL}$ and MAM received financial support from GSK to support the research described in the manuscript. TC is employed by and/or a stockholder of GSK. The remaining authors declare that they have no competing interests.

Received: 14 February 2012 Revised: 10 May 2012

Accepted: 7 June 2012 Published: 7 June 2012

\section{References}

1. Ferrer-Soler L, Vazquez-Martin A, Brunet J, Menendez JA, De Llorens R, Colomer R: An update of the mechanisms of resistance to EGFR-tyrosine kinase inhibitors in breast cancer: Gefitinib (Iressa)-induced changes in the expression and nucleo-cytoplasmic trafficking of HER-ligands [review]. Int J Mol Med 2007, 20:3-10.

2. Blackwell KL, Burstein HJ, Storniolo AM, Rugo H, Sledge G, Koehler M, Ellis C, Casey M, Vukelja S, Bischoff J, Baselga J, O'Shaughnessy J: Randomized study of Lapatinib alone or in combination with trastuzumab in women with ErbB2-positive, trastuzumab-refractory metastatic breast cancer. J Clin Oncol 2010, 28:1124-1130.

3. Scheuer W, Friess T, Burtscher H, Bossenmaier B, Endl J, Hasmann M: Strongly enhanced antitumor activity of trastuzumab and pertuzumab combination treatment on HER2-positive human xenograft tumor models. Cancer Res 2009, 69:9330-9336.

4. Baselga J, Gelmon KA, Verma S, Wardley A, Conte P, Miles D, Bianchi G, Cortes J, McNally VA, Ross GA, Fumoleau P, Gianni L: Phase II trial of pertuzumab and trastuzumab in patients with human epidermal growth factor receptor 2-positive metastatic breast cancer that progressed during prior trastuzumab therapy. J Clin Oncol 2010, 28:1138-1144.

5. Hsieh AC, Moasser MM: Targeting HER proteins in cancer therapy and the role of the non-target HER3. Br J Cancer 2007, 97:453-457.

6. Moasser MM: The oncogene HER2: its signaling and transforming functions and its role in human cancer pathogenesis. Oncogene 2007, 26:6469-6487.

7. Dikic I: Mechanisms controlling EGF receptor endocytosis and degradation. Biochem Soc Trans 2003, 31:1178-1181.

8. Wiley HS: Trafficking of the ErbB receptors and its influence on signaling. Exp Cell Res 2003, 284:78-88.

9. Bazley LA, Gullick WJ: The epidermal growth factor receptor family. Endocr Relat Cancer 2005, 12(Suppl 1):S17-S27.

10. Sorkin A, Goh LK: Endocytosis and intracellular trafficking of ErbBs. Exp Cell Res 2008, 314:3093-3106.

11. Breuleux M, Schoumacher F, Rehn D, Kung W, Mueller H, Eppenberger U: Heregulins implicated in cellular functions other than receptor activation. Mol Cancer Res 2006, 4:27-37.

12. Jones SM, Foreman SK, Shank BB, Kurten RC: EGF receptor downregulation depends on a trafficking motif in the distal tyrosine kinase domain. Am J Physiol Cell Physiol 2002, 282:C420-C433.

13. Morse MA, Wei J, Hartman Z, Xia W, Ren XR, Lei G, Barry WT, Osada T, Hobeika AC, Peplinski S, Jiang H, Devi GR, Chen W, Spector N, Amalfitano A, Lyerly HK, Clay TM: Synergism from combined immunologic and pharmacologic inhibition of HER2 in vivo. Int J Cancer 2010, 126:2893-2903.

14. Piechocki MP, Pilon SA, Wei WZ: Quantitative measurement of anti-ErbB-2 antibody by flow cytometry and ELISA. J Immunol Methods 2002, 259:33-42.
15. Yang $X L$, Huang $Y Z$, Xiong WC, Mei L: Neuregulin-induced expression of the acetylcholine receptor requires endocytosis of ErbB receptors. $\mathrm{Mol}$ Cell Neurosci 2005, 28:335-346.

16. Hartman ZC, Wei J, Osada T, Glass O, Lei G, Yang XY, Peplinski S, Kim DW, Xia W, Spector N, Marks J, Barry W, Hobeik A, Devi G, Amalfitano A, Morse MA, Lyerly HK, Clay TM: An adenoviral vaccine encoding full-length inactivated human Her2 exhibits potent immunogenicty and enhanced therapeutic efficacy without oncogenicity. Clin Cancer Res 2010, 16:1466-1477.

17. Akiyama T, Matsuda S, Namba Y, Saito T, Toyoshima K, Yamamoto T: The transforming potential of the c-erbB-2 protein is regulated by its autophosphorylation at the carboxyl-terminal domain. Mol Cell Biol 1991, 11:833-842.

18. Messerle K, Schlegel J, Hynes NE, Groner B: NIH/3T3 cells transformed with the activated erbB-2 oncogene can be phenotypically reverted by a kinase deficient, dominant negative erbB-2 variant. Mol Cell Endocrinol 1994, 105:1-10.

19. Ben-Levy R, Paterson HF, Marshall CJ, Yarden Y: A single autophosphorylation site confers oncogenicity to the Neu/ErbB-2 receptor and enables coupling to the MAP kinase pathway. EMBO J 1994, 13:3302-3311.

20. Wei WZ, Shi WP, Galy A, Lichlyter D, Hernandez S, Groner B, Heilbrun L, Jones RF: Protection against mammary tumor growth by vaccination with full-length, modified human ErbB-2 DNA. Int J Cancer 1999, 81:748-754.

21. Segatto O, Lonardo F, Pierce JH, Bottaro DP, Di Fiore PP: The role of autophosphorylation in modulation of erbB-2 transforming function. New Biol 1990, 2:187-195.

22. Muthuswamy SK, Gilman M, Brugge JS: Controlled dimerization of ErbB receptors provides evidence for differential signaling by homo- and heterodimers. Mol Cell Biol 1999, 19:6845-6857.

23. Hazan R, Margolis B, Dombalagian M, Ullrich A, Zilberstein A, Schlessinger J: Identification of autophosphorylation sites of HER2/neu. Cell Growth Differ 1990, 1:3-7.

24. Junttila TT, Akita RW, Parsons K, Fields C, Lewis Phillips GD, Friedman LS, Sampath D, Sliwkowski MX: Ligand-independent HER2/HER3/PI3K complex is disrupted by trastuzumab and is effectively inhibited by the PI3K inhibitor GDC-0941. Cancer Cell 2009, 15:429-440.

25. Scaltriti M, Verma C, Guzman M, Jimenez J, Parra JL, Pedersen K, Smith DJ, Landolfi S, Ramon y, Cajal S, Arribas J, Baselga J: Lapatinib, a HER2 tyrosine kinase inhibitor, induces stabilization and accumulation of HER2 and potentiates trastuzumab-dependent cell cytotoxicity. Oncogene 2009, 28:803-814.

26. Gijsen M, King P, Perera T, Parker PJ, Harris AL, Larijani B, Kong A: HER2 phosphorylation is maintained by a PKB negative feedback loop in response to anti-HER2 herceptin in breast cancer. PLOS Biol 2010, 8: e1000563.

27. Neve RM, Chin K, Fridlyand J, Yeh J, Baehner FL, Fevr T, Clark L, Bayani N, Coppe JP, Tong F, Speed T, Spellman PT, DeVries S, Lapuk A, Wang NJ, Kuo WL, Stilwell JL, Pinkel D, Albertson DG, Waldman FM, McCormick F, Dickson RB, Johnson MD, Lippman M, Ethier S, Gazdar A, Gray JW: A collection of breast cancer cell lines for the study of functionally distinct cancer subtypes. Cancer Cell 2006, 10:515-527.

28. Giri DK, Ali-Seyed M, Li LY, Lee DF, Ling P, Bartholomeusz G, Wang SC, Hung MC: Endosomal transport of ErbB-2: mechanism for nuclear entry of the cell surface receptor. Mol Cell Biol 2005, 25:11005-11018.

29. Worthylake R, Wiley HS: Structural aspects of the epidermal growth factor receptor required for transmodulation of erbB-2/neu. J Biol Chem 1997, 272:8594-8601.

30. Worthylake R, Opresko LK, Wiley HS: ErbB-2 amplification inhibits downregulation and induces constitutive activation of both ErbB-2 and epidermal growth factor receptors. J Biol Chem 1999, 274:8865-8874.

31. Kornilova ES, Taverna D, Hoeck W, Hynes NE: Surface expression of erbB-2 protein is post-transcriptionally regulated in mammary epithelial cells by epidermal growth factor and by the culture density. Oncogene 1992, 7:511-519.

32. Katz M, Shtiegman K, Tal-Or P, Yakir L, Mosesson Y, Harari D, Machluf Y, Asao H, Jovin T, Sugamura K, Yarden Y: Ligand-independent degradation of epidermal growth factor receptor involves receptor ubiquitylation and $\mathrm{Hgs}$, an adaptor whose ubiquitin-interacting motif targets ubiquitylation by Nedd4. Traffic 2002, 3:740-751. 
33. Chin $L S$, Raynor MC, Wei $X$, Chen $H Q$, Li L: Hrs interacts with sorting nexin 1 and regulates degradation of epidermal growth factor receptor. $J$ Biol Chem 2001, 276:7069-7078.

34. Cardullo RA: Theoretical principles and practical considerations for fluorescence resonance energy transfer microscopy. Methods Cell Biol 2007, 81:479-494.

35. Kallal L, Gagnon AW, Penn RB, Benovic JL: Visualization of agonist-induced sequestration and down-regulation of a green fluorescent proteintagged $\beta 2$-adrenergic receptor. J Biol Chem 1998, 273:322-328.

36. Mellman I: Endocytosis and molecular sorting. Annu Rev Cell Dev Biol 1996, 12:575-625.

37. Hansen SH, Sandvig K, van Deurs B: Clathrin and HA2 adaptors: effects of potassium depletion, hypertonic medium, and cytosol acidification. J Cell Biol 1993, 121:61-72.

38. Yuan CX, Lasut AL, Wynn R, Neff NT, Hollis GF, Ramaker ML, Rupar MJ, Liu P, Meade R: Purification of Her-2 extracellular domain and identification of its cleavage site. Protein Expr Purif 2003, 29:217-222.

39. Tikhomirov O, Carpenter G: Geldanamycin induces ErbB-2 degradation by proteolytic fragmentation. J Biol Chem 2000, 275:26625-26631.

40. Hamilton E, Blackwell K, Hobeika AC, Clay TM, Broadwater G, Ren XR, Chen W, Castro H, Lehmann F, Spector N, Wei J, Osada T, Lyerly HK: Phase I clinical trial of HER2-specific immunotherapy with concomitant HER2 kinase inhibition. J Transl Med 2012, 10:28.

41. Ben-Kasus T, Schechter B, Lavi S, Yarden Y, Sela M: Persistent elimination of ErbB-2/HER2-overexpressing tumors using combinations of monoclonal antibodies: relevance of receptor endocytosis. Proc Natl Acad Sci USA 2009, 106:3294-3299.

42. Lerdrup M, Hommelgaard AM, Grandal M, van Deurs B: Geldanamycin stimulates internalization of ErbB2 in a proteasome-dependent way. $J$ Cell Sci 2006, 119:85-95.

43. Austin CD, De Maziere AM, Pisacane PI, van Dijk SM, Eigenbrot C, Sliwkowski MX, Klumperman J, Scheller RH: Endocytosis and sorting of ErbB2 and the site of action of cancer therapeutics trastuzumab and geldanamycin. Mol Biol Cell 2004, 15:5268-5282.

44. Barr DJ, Ostermeyer-Fay AG, Matundan RA, Brown DA: Clathrinindependent endocytosis of ErbB2 in geldanamycin-treated human breast cancer cells. J Cell Sci 2008, 121:3155-3166.

45. Marx C, Held JM, Gibson BW, Benz CC: ErbB2 trafficking and degradation associated with K48 and K63 polyubiquitination. Cancer Res 2010, 70:3709-3717.

46. Small EJ, Schellhammer PF, Higano CS, Redfern CH, Nemunaitis JJ, Valone FH, Verjee SS, Jones LA, Hershberg RM: Placebo-controlled phase III trial of immunologic therapy with sipuleucel-T (APC8015) in patients with metastatic, asymptomatic hormone refractory prostate cancer. J Clin Oncol 2006, 24:3089-3094.

47. Kantoff PW, Schuetz TJ, Blumenstein BA, Glode LM, Bilhartz DL, Wyand M, Manson K, Panicali DL, Laus R, Schlom J, Dahut WL, Arlen PM, Gulley JL, Godfrey WR: Overall survival analysis of a phase II randomized controlled trial of a Poxviral-based PSA-targeted immunotherapy in metastatic castration-resistant prostate cancer. J Clin Oncol 2010, 28:1099-1105.

doi:10.1186/bcr3204

Cite this article as: Ren et al:: Polyclonal HER2-specific antibodies induced by vaccination mediate receptor internalization and degradation in tumor cells. Breast Cancer Research 2012 14:R89.

\section{Submit your next manuscript to BioMed Central and take full advantage of:}

- Convenient online submission

- Thorough peer review

- No space constraints or color figure charges

- Immediate publication on acceptance

- Inclusion in PubMed, CAS, Scopus and Google Scholar

- Research which is freely available for redistribution 